\title{
Eco-physiological consequences of overwintering underground
}

\author{
Raymond Huey ${ }^{1}$, Liang $\mathrm{Ma}^{2}$, Ofir Levy ${ }^{3}$, and Michael Kearney ${ }^{4}$ \\ ${ }^{1}$ University of Washington \\ ${ }^{2}$ Princeton University \\ ${ }^{3}$ Tel Aviv University \\ ${ }^{4}$ University of Melbourne
}

June 9, 2020

\begin{abstract}
Ectotherms in cold environments often spend long winters underground. In 1941 Raymond Cowles proposed a novel ecological trade-off involving depth at which ectotherms overwintered. On warm days, only shallow reptiles could detect warming soils and become active; but on cold days, they risked freezing. Cowles discovered that most reptiles at a desert site overwintered at shallow depths. To extend his study we compiled hourly soil temperatures ( 5 depths, 90 sites, continental USA) and physiological data, and then simulated consequences of overwintering at fixed depths. In warm localities shallow ectotherms have low energy costs and largest reserves in spring; but in cold localities, shallow ectotherms risk freezing. Ectotherms shifting to the coldest depth potentially reduce energy expenses, but paradoxically sometimes have higher expenses than those at fixed depths. Biophysical simulations for one desert site predict that shallow ectotherms should have elevated opportunities for mid-winter activity but may need to move deep to digest captured food. Our simulations generate testable eco-physiological predictions but rely on physiological responses to acute cold rather to natural cooling profiles. Furthermore, testing ecological predictions requires natural-history data that do not exist. Thus, our simulation approach uncovers "unknown unknowns" and suggests research agendas for studying ectotherms overwintering underground.
\end{abstract}

\section{Hosted file}

Huey_et_al.pdf available at https://authorea.com/users/331436/articles/458120-ecophysiological-consequences-of-overwintering-underground 